Case report

\title{
OCCURRENCE OF HAEMANGIOSARCOMA ON THE GINGIVA OF A CALF: A CASE REPORT
}

\author{
S. AZIZI ${ }^{1}$, M. AMIRMOHAMMADI ${ }^{2}$, R. KHEIRANDISH ${ }^{1}$, \\ Z. DAVOODIAN ${ }^{3} \&$ M. GOODARZI ${ }^{4}$ \\ ${ }^{1}$ Department of Pathobiology, Faculty of Veterinary Medicine, Shahid Bahonar \\ University of Kerman, Kerman, Iran; ${ }^{2}$ Jiroft Branch, Islamic Azad University, Young \\ Researchers Club, Jiroft, Kerman, Iran; ${ }^{3}$ Graduated from the Faculty of Veterinary \\ Medicine, Shahid Bahonar University of Kerman, Kerman, Iran; ${ }^{4}$ Department of \\ Clinical Sciences, Faculty of Veterinary Medicine, Islamic Azad University, \\ Shahrekord Branch, Shahrekord, Iran
}

\section{Summary}

Azizi, S., M. Amirmohammadi, R. Kheirandish, Z. Davoodian \& M. Goodarzi, 2017. Occurrence of haemangiosarcoma on the gingiva of a calf: A case report. Bulg. J. Vet. Med., 20, No 2, 183-188.

\begin{abstract}
Haemangiosarcoma is a malignant endothelial cell tumour with rapid growth and poor prognosis. In animals, haemangiosarcoma is frequently reported in dogs as a visceral tumour. The present study describes a gingival haemangiosarcoma in a 2-month-old, female native breed calf with a tumour likemass on the gingiva. The owner had noticed the mass 2 weeks after birth due to salivation, bleeding and halitosis. It had rapid growth and caused anorexia and weight loss in the animal. Histopathologic examination showed a lot of thin-walled, irregular blood vessels lined by a single and less commonly two layers of endothelial cells. The lining cells were with spindle or ovoid shape with vesicular to hyperchromatic nuclei and prominent nucleoli. There were remarkable thrombi in some vessels. The reported lesions were diagnosed as haemangiosarcoma based on histopathologic characteristics such as irregular vascular canals and polymorphism of neoplastic endothelial cells. Haemangiosarcoma is rare in the oral cavity of cattle.
\end{abstract}

Key words: calf, haemangiosarcoma, histopathology

Haemangiosarcoma is a mesenchymal tumour that originates from transformed endothelial cell and may develops in every tissue (Muten, 2002). Haemangiosarcomas appear as different clinical forms including focal, local infiltrative and dis- seminated masses affecting multiple organs (Southwood et al., 2000). Haemangiosarcomas usually progress rapidly and are often associated with metastasis. Prognosis of this tumour is poor (Smith, 2003; Mulliken \& Enjolras, 2004). In animals, 
haemangiosarcoma develops more frequently in dogs than in other species and its prevalence rate is $7 \%$ of all canine tumours (Helfand, 2008). In dogs, this tumour is reported commonly as a visceral tumour mainly in the spleen (Pulley \& Stannard, 1990). Canine haemangiosarcoma is common and reported especially in the German shepherd and Golden Retriever breeds (Muten, 2002). The tumour is less frequently seen in the cat (Multari et al., 2002), and rarely in large domestic animals such as horses (Wegge et al., 2009; Ferrucci et al., 2012), cattle (Poulsen et al., 2008; Stock et al., 2011), goats (Collier et al., 2013) and sheep (Preziuso et al., 2002).

Haemangiosarcoma is extremely rare in the oral cavity (Head et al., 2002). Occurrence of blood vascular tumours in cattle is uncommon (Urdaz et al., 2001; Poulsen et al., 2008). The present study describes the occurence of a gingival haemangiosarcoma in a calf.

A 2-month-old, female native breed calf with a tumour like-mass on the gingiva was referred to the Department of Pathology, Shahid Bahonar University of Kerman, Iran. The owner had noticed to the mass 2 weeks after birth due to salivation, bleeding and halitosis. It developed rapidly and caused anorexia and weight loss in the calf.

Gross examination of the oral cavity showed a prominent two parts-mass located on the left side of mandibular gingiva affecting both the buccal and the lingual side of the mandible. The rostral part of the mass was $3 \times 3 \times 2 \mathrm{~cm}$, gray, keratinised with ulcerated surface, that covered the incisors and protruded outside the mouth. The caudal part had pink colour, size $6 \times 2 \times 4 \mathrm{~cm}$ and extended on the lingual side of the mandible but sublingual tissues were not involved (Fig. 1). On gross ex- amination, the mass was friable and had tendency to bleeding instantly.

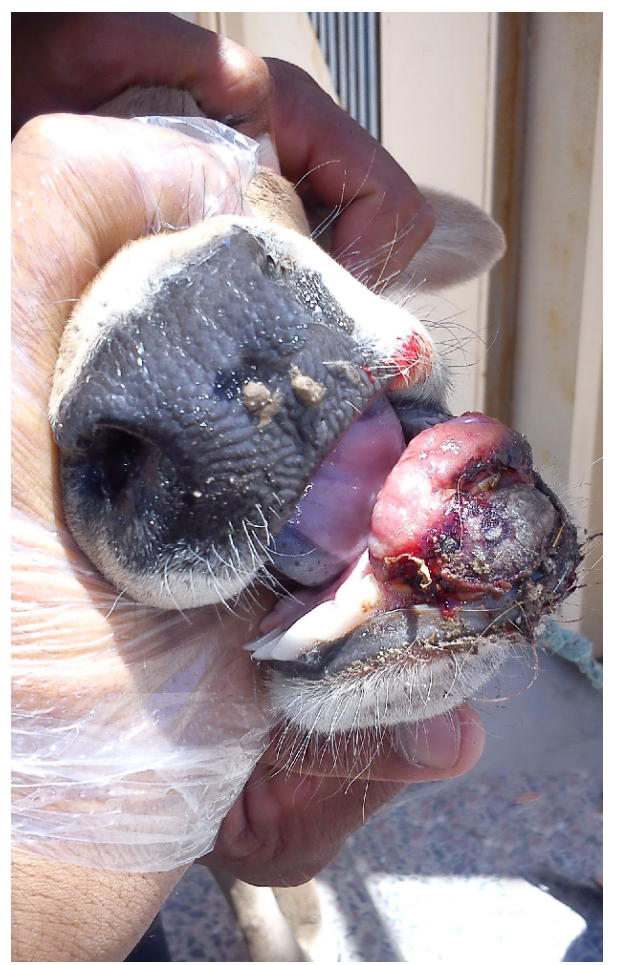

Fig. 1. Gingival haemangiosarcoma in calf covering the buccal and the lingual side of the mandible.

The tumour-like lesion was surgically removed and tissue samples were fixed in $10 \%$ neutral buffered formalin. Then, the specimens were processed using the standard procedure. Sections of $5 \mu \mathrm{m}$ thickness were stained with haematoxylin and $\operatorname{eosin}(\mathrm{H} / \mathrm{E})$ for microscopic investigation.

Histopathological examination showed that the mandibular mass was composed of numerous thin-walled, irregular blood vessels lined by a single and less commonly two layers of endothelial cells (Fig. 2 ). The lining cells had spindle or ovoid shape with vesicular to hyperchromatic nuclei and prominent nucleoli (Fig. 3). The endothelial cells were bulged into the 
vascular lumens and few erythrocytes were visible there. Some cells similar to vascular elements were seen in the stroma. In some areas, the vascular structures with hardly visible lumens or as a solid sheets without lumen were formed. Mitotic figures were frequently visible. The stroma varied from a delicate fibrous network to myxomatous stroma. In some areas, the tumours were highly cellular.

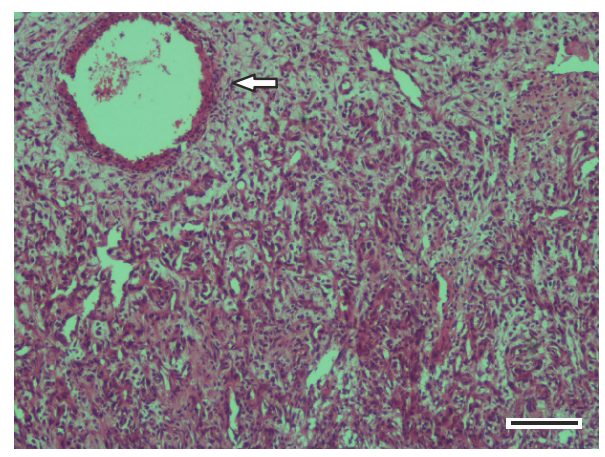

Fig. 2. A lot of thin-walled, irregular blood vessels lined by a single and less commonly two layers (arrow) of endothelial cells $(\mathrm{H} / \mathrm{E}$, $\mathrm{Bar}=100 \mu \mathrm{m})$.

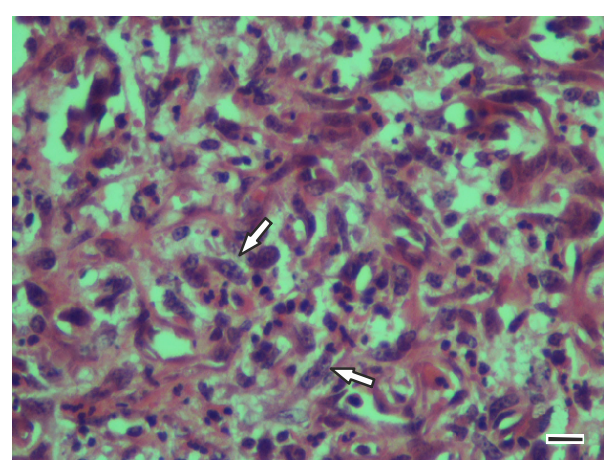

Fig. 3. Polymorphism of transformed endothelial cells including hyperchromatic to vesicular nuclei with prominent nucleoli (arrows) (H/E, Bar $=10 \mu \mathrm{m})$.

The endothelium of some vessels showed crowded nuclei due to mitotic activity with intraluminal papillary proliferation narrowing the lumen of the vessels (Fig. 4). There were remarkable thrombi in some vessels (Fig. 5). The overlying epithelium of the gingival mass was ulcerated. A large number of neutrophils and necrotic tissues were observed in the damaged mucosa which extended into the stromal tumour between the blood vessels. Post operative oral examination after a month revealed a gross recurrence of the gingival mass. The lesion reported here was diagnosed as haemangiosarcoma based on histopathological characteristics such as irregular vascular canals and polymorphism of neoplastic endothelial cells.

Haemangiosarcoma occurs as visceral and nonvisceral forms. Visceral haemangiosarcomas have an aggressive behaviour with a poor prognosis and appear as multicentic foci more common in the spleen, liver, lungs, and right auricle. Haemoperitoneum or haemopericardium is caused due to rupture of tumour nodules or masses in visceral organs and lead to death.

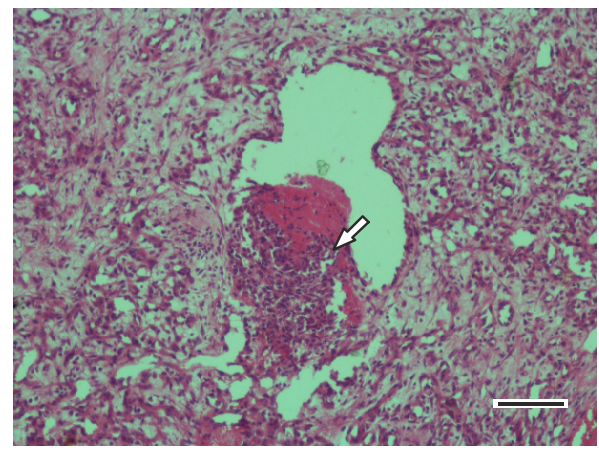

Fig. 4. Intraluminal proliferation of endothelial cells causes narrowing the vascular space (arrow) $(\mathrm{H} / \mathrm{E}, \mathrm{Bar}=100 \mu \mathrm{m})$.

The present study described gingival haemangiosarcoma in a 2-month-old female calf. The mass was located on the mandible near the incisors and seen by the owner 2 weeks after birth. Histopatholo- 


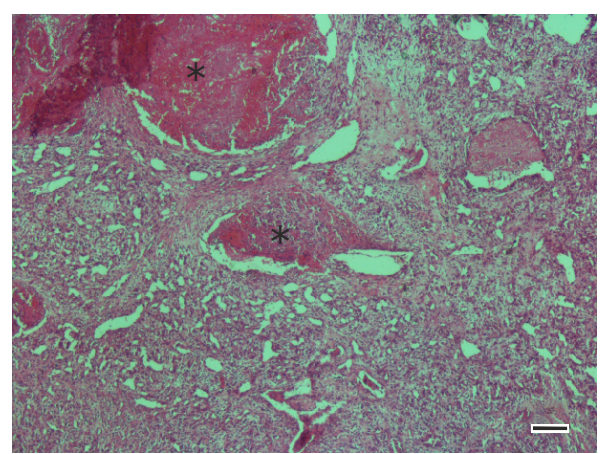

Fig. 5. Irregular vascular spaces associated with remarkable thrombi (asterisks) in gingival haemangiosarcoma $(\mathrm{H} / \mathrm{E}, \mathrm{Bar}=100 \mu \mathrm{m})$.

gically, many thin-walled vessels were observed. Vessels of different size covered with polymorphic endothelial cells were evidence of malignancy. The single tumours are described more at birth or within 3 days after birth. Female cattle are affected more than males and the incisors region of the mandible is the common site of the tumour (Muten, 2002). Our pathologic findings were consistent with previous studies in different tissues of cattle including cutaneous haemangiosarcoma (Urdaz et al., 2001), external nares (Queen et al., 1992), osseous haemangiosarcoma (Zachary et al., 1981; Guard \& Wilkinson, 1984), CNS (Sutton \& McLennan, 1982), mandibular haemangiosarcoma (Poulsen et al., 2008; Sumida et al., 2012), cutaneous haemangiosarcoma (Urdaz et al., 2001).

Relatively few reports of haemangiosarcoma have been documented in adult or old age cattle (Pulley \& Stannard, 1990). Stock et al. (2011) described disseminated haemangiosarcoma in a 9-yearold Brown Swiss cow with a history of anorexia, weakness and weight loss. Haematological and blood biochemistry analysis revealed a regenerative anaemia, thrombocytopenia, leukopaenia with a lymphopaenia and elevated liver enzymes. They observed disseminated masses of haemangiosarcoma in the liver and spleen with suspected metastasis to the lungs, kidney, nasal turbinates, right corneal limbus, and right perirenal lymph nodes. Poulsen et al. (2008) studied primary mandibular haemangiosarcoma in a 2-year-old Jersey bull. Extensive haemorrhagic nodules occupied the distal ramus of the mandible primarily. In addition, pinpoint to $4-\mathrm{cm}$ red nodules were distributed throughout the pleural and lung parenchyma. Histopathologically, the haemorrhagic nodules were made of irregular cords of pleomorphic endothelial cells with abundant, amphophilic cytoplasm, irregular ovoid nuclei and variable number (0-3) of prominent nucleoli.

Occurrence of haemangiosarcoma in young animals is rare. Badylak (1983) reported congenital multifocal haemangiosarcoma in a stillborn female Hereford calf with distribution in the skin, skeletal muscle, bone, kidney, spleen, mesentery, liver, lung, and heart. Also, haemangiosarcoma in the left side of the neck muscle in a 4-month-old Friesian bull calf (Vermunt \& Thompson, 2001) and bone of a 10-month-old steer (Zachary et al., 1981) are other reports in young calves.

In humans, angiosarcoma of the oral cavity is extremely rare (Loudon et al., 2000; Favia et al., 2002; Terada, 2011). Various tissues of the oral cavity could be affected by anigosarcoma. Fanburg-Smith et al. (2003) reported 22 cases of primary angiosarcoma in the oral region including 9 cases in the tongue, 4 in the parotid gland, 4 in the lip, 3 in the submandibular gland, and 1 in the palate. Men and women were equally affected. The symptoms were bleeding from tumour mass.

The etiology of haemangioma is unknown. In humans, these tumours have 
been associated with exposure to thorium dioxide, arsenicals, and vinyl chloride in workers of PVC industry (Jubb et al., 2007). In veterinary medicine, vascular tumours have been produced by inhalation of radioisotopes in dogs, and type $\mathrm{C}$ viruses have been demonstrated in cutaneous angioma of cats (Muten, 2002).

Haemangiosarcoma should be differentiated from vascular hamartomas. Hamartomas are local overgrowth of mature normal blood vessels but disorganised that occur frequently at birth time in calves or young animals (Wilson, 1990; Mohammadi et al., 2007). In this study, presence of polymorphism and nuclear atypia in endothelial cells ruled out haemangiosarcoma from vascular hamartoma.

\section{REFERENCES}

Badylak, S. F., 1983. Congenital multifocal hemangiosarcoma in a stillborn calf. Veterinary Pathology, 20, 245-247.

Collier, J. R., S. R. Byers, P. A. Schaffer, D. R. Worley, E. J. Ehrhart, C. G. Duncan, A. N. Grossman, T. Holt \& R. J. Callan, 2013. Infiltrative cutaneous hemangiolipoma in a goat. Veterinary Medicine International, 2013, doi: 10.1155/2013/ 942351.

Fanburg-Smith, J. C., M. A. Furlong \& E. L. Childers, 2003. Oral and salivary gland angiosarcoma: A clinicopathologic study of 29 cases. Modern Patholology, 16, 263271.

Favia, G., L. Lo Muzio, R Serpico \& E. Maiorano, 2002. Angiosarcoma of the head and neck with intraoral presentation: a clinico-pathological study of four cases. Oral Oncology, 38, 757-762.

Ferrucci, F., A. Vischi, E. Zucca, G. Stancari, A. Boccardo, M. Rondena, P. Riccaboni \& E. Ferro, 2012. Multicentric hemangiosarcoma in the horse: A case report. Journal of Equine Veterinary Science, 32, 6571.

BJVM, 20, No 2
Guard, C. \& J. E. Wilkinson, 1984. Hemangiosarcoma in a cow. Journal of the American Veterinary Medical Association, 185, 789-790.

Head, K. W., R. W. Else \& R. R. Dubielzing, 2002. Tumors and tumor like lesions of vascular tissue: Tumors of Domestic Animals, $4^{\text {th }}$ edn, Iowa State Press.

Helfand, S. C., 2008. Canine hemangiosarcoma: A tumor of contemporary interest. Cancer Therapy, 6, 457-462.

Jubb K. V. F., P. C. Kennedy \& N. Palmer, 2007. Pathology of Domestic Animals. $5^{\text {th }}$ edn, Academic Press, NY, USA.

Loudon, J. A., M. L. Billy, B. R. DeYoung \& C. M. Allen, 2000. Angiosarcoma of the mandible: a case report and review of the literature. Oral Surgery, Oral Medicine, Oral Pathology, Oral Radiology, and Endodontology, 89, 471-476.

Mohammadi, G. R., M. Maleki \& K. Sardari, 2007. Gingival vascular hamartoma in a young Holstein calf. Comparative Clinical Pathology, 16, 73-75.

Mulliken, J. B. \& O. Enjolras, 2004. Congenital hemangiomas and infantile hemangioma: Missing links. Journal of the American Academy of Dermatology, 50, 875882.

Multari, D, M. Vascellari \& F. Mutinelli, 2002. Hemangiosarcoma of the third eyelid in a cat. Veterinary Ophthalmology, 5, 273-276.

Muten, D. J., 2002. Tumors in Domestic animals, $4^{\text {th }}$ edn, Iowa State, Ames.

Poulsen, K. P., A. C. McSloy, M. Perrier, M. A. Prichard, H. Steinberg \& S. D. Semrad, 2008. Primary mandibular hemangiosarcoma in a bull. The Canadian Veterinary Journal, 49, 901-903.

Preziuso, S., E. Taccini, G. Rossi, G. Braca \& G. Renzoni, 2002. Cutaneous Haemangiosarcoma in a sheep: morphological, histopathological and immunohistochemical observations. Journal of Comparative Pathology, 127, 72-75. 
Pulley, L. \& A. A. Stannard, 1990. Tumors of the skin and soft tissues. In: Tumors in Domestic Animals, Moulton J. (ed)., $3^{\text {rd }}$ edition, University of California Press, Los Angeles, pp. 23-87.

Queen, W. G., M. A. Masterson \& S. E. Weisbrode, 1992. Hemangiosarcoma of the external nares in a cow. Journal of the American Veterinary Medical Association, 201, 1411-1412.

Smith, A. N., 2003. Hemangiosarcoma in dogs and cats. Veterinary Clinics of North America: Small Animal Practice, 33, 533-552.

Southwood, L. L., H. C. Schott, C. J. Henry, F. A. Kennedy, M. T. Hines, R. J. Geor \& D. M. Hassel, 2000. Disseminated hemangiosarcoma in the horse: 35 cases. Journal of Veterinary Internal Medicine, 14, 105109.

Stock, M. L., B. I. Smith \& J. B. Engiles, 2011. Disseminated hemangiosarcoma in a cow. The Canadian Veterinary Journal, 52, 409-413.

Sumida, T., R. Murase, Y. Fujita, A. Ishikawa \& H. Hamakawa, 2012. Epulis-like gingival angiosarcoma of the mandible: A case report. International Journal of Clinical and Experimental Pathology, 5, 830833.

Sutton, R. H. \& M. W. McLennan, 1982. Hemangiosarcoma in a cow. Veterinary $\mathrm{Pa}$ thology, 19, 456-458.

Terada, T., 2011. Angiosarcoma of the mandibular gingiva. International Journal of Clinical and Experimental Pathology, 4, 791-793.
Urdaz, J. H., J. W. Tyler, C. J. Henry, P. Gautz, J. R. Turk \& S. E. Turnquist, 2001. Primary cutaneous hemangiosarcoma in a cow. The Veterinary Record, 149, 306307.

Vermunt, J. J. \& K. G. Thompson, 2001. Hemangiosarcoma in a 4-month-old calf. New Zealand Veterinary Journal, 49, 120-121.

Wegge, B., M. Vandecasteele, F. Gasthuys, K. Chiers \& R. Ducatelle, 2009. Hemangiosarcoma of the third eyelid in a horse. Vlaams Diergeneeskundig Tijdschrift, 78, 436-439.

Wilson, R. B., 1990. Gingival vascular hamartoma in three calves. Journal of Veterinary Diagnostic Investigation, 2, 338-339.

Zachary, J. F., M. G. Jones \& W. A. Wolff, 1981. Multicentric osseous hemangiosarcoma in a Chianina-Angus steer. Veterinary Pathology, 18, 266-270.

Paper received 08.09.2015; accepted for publication 12.11.2015

\section{Correspondence:}

Shahrzad Azizi

Department of Pathobiology,

Faculty of Veterinary Medicine,

Shahid Bahonar University of Kerman,

Kerman, Iran 